http://jmscr.igmpublication.org/home/

ISSN (e)-2347-176x ISSN (p) 2455-0450

crossref DOI: https://dx.doi.org/10.18535/jmscr/v8i10.50

\title{
Demographic Correlation with Upper Gastrointestinal Endoscopy Findings - A Prospective Study
}

Authors

\author{
Dr Kamal Kumar. K ${ }^{1 *}$, Dr J.Kabalimurthy, ${ }^{2}$ Dr S.Sundar Prakash ${ }^{3}$, \\ Dr V.B. Mary Prescilla ${ }^{1}$, Dr M. Aravindhan ${ }^{1}$, Dr A. Jospin Amala ${ }^{1}$ \\ ${ }^{1}$ Junior Resident, ${ }^{2}$ Professor and Chief, ${ }^{3}$ Associate Professor, \\ Rajah Muthiah Medical College \& Hospital, Annamalai University, Tamil Nadu, India \\ *Corresponding Author \\ Dr Kamal Kumar. K
}

Junior Resident, Rajah Muthiah Medical College \& Hospital, Annamalai University, Tamil Nadu, India

\begin{abstract}
Aims and Objectives: Uninvestigated dyspepsia is one of the common presentation in a surgical department. The prevalence and predictability of the upper gastrointestinal findings in a case of uninvestigated dyspeptic patient based on age and sex of the patient varies. A study was undertaken to study. Age and sex wise occurrence of gastro esophageal reflux disease in our community.

Materials and Methods: Prospective observational study was conducted on 150 patients aged between 18 - 80 years presenting with untreated, uninvestigated and uncomplicated dyspepsia admitted with upper gastrointestinal symptoms.After obtaining ethical committee approval, and getting informed and signed consent from the patients upper gastro-intestinal endoscopy was performed and documented.

Results:

- Highest prevalence of late onset dyspepsia in the age group of 41-50years (24.6\%)

- Dyspepsia was more common in males (61.3\%) when compared to females

- Clinically significant endoscopic findings were observed in $71.3 \%$ of patients with uninvestigated dyspepsia.

Out of 150 patients, there were 92 (61.3\%) male patients, 58 (38.7\%) female patients, age ranging from 18 years to 80 years. The mean age of the patients in this study with more GERD was found to be between 31 40 years.

Most patients presented with a complex of three or more dyspeptic symptoms and the symptom profile was not predictive of the endoscopic findings. However, the high prevalence of gastritis (28.7\%), suggests that most patients of both sexes presenting with uninvestigated dyspepsia can be safely managed initially with acid suppressive drugs.

Conclusion: Clinically significant endoscopic findings were observed in $71.3 \%$ of patients with uninvestigated dyspepsia. Most patients presented with a complex of three or more dyspeptic symptoms and the symptom profile was not predictive of the endoscopic findings. A larger number of inflammatory lesions as a result of increased acid production and low incidence of malignancy in the study group. It is suggested that the uninvestigated patients with dyspepsia may be initially managed medically with acid suppressive therapy.

Endoscopy may be undertaken in patients with recurrent symptoms or in whom drug therapy fails.

Keywords: Upper GI endoscopy; dyspepsia; Gastro eosophageal reflex disease.
\end{abstract}




\section{Introduction}

Dyspepsia (also called uninvestigated dyspepsia) had been defined by the Rome working teams as pain or discomfort centered in the upper abdomen. Pain in the central portion of the abdomen is a key symptom, pain located in other areas or related to defecation is excluded. Discomfort is considered to be distinct from pain; however, both often coexist and the distinction may in part be culturally driven. Discomfort has been defined as a subjective negative feeling that may include a variety of symptoms such as fullness in the upper abdomen, early satiety, bloating or nausea.

The definition of dyspepsia includes patients who have intermittent or continuous symptoms and does not specify the duration of symptoms. Thus dyspepsia may be of short or long duration, but acute self-limited dyspepsia does not usually require investigation and will not be considered furtherhere.

The majority of patients who present with chronic dyspepsia have no obvious underlying explanation despite appropriate investigation; these cases are currently labeled as having non-ulcer (or functional) dyspepsia, although this is likely to be a heterogeneous condition. The pathophysiology of functional dyspepsia remains relatively poorly defined, but sensory and motor disorders of the stomach and duodenum appear to play a central role in at least a subset of cases.

\section{Materials and Methods}

Prospective observational study was conducted on 150 patients aged between $18-80$ years presenting with untreated, uninvestigated and uncomplicated dyspepsia admitted with upper gastrointestinal symptoms. After obtaining ethical committee approval, and getting informed and signed consent from the patients upper gastrointestinal endoscopy was performed and documented The patients of both sexes admitted with upper gastrointestinal symptoms will be studied in terms of: History; Blood investigations: complete heamogram, random blood sugar, HbsAg, HIV; Radiological investigations: $\mathrm{X}$ ray Chest PA view, Ultrasound abdomen and pelvis. 150 patients aged between $18-80$ years presenting with uninvestigated, untreated and uncomplicated dyspepsia were enrolled and evaluated in the study. Patients aged less than 18 years, patients on Proton pump inhibitors, patients who are known cases of chronic pancreatitis and liver disease, patients on NSAID's for more than one month duration, patients who had received Anti-Helicobacter pylori treatment and unwilling or unfit patients for endoscopy were excluded from the study.

All patients underwent upper gastro-intestinal endoscopy to document the various findings. Biopsies were taken in every patient from the gastric antrum and pathological site. The biopsy specimen was subjected to histo pathological examination for confirmation. The findings were documented and analysed.

\section{Study}

A total of 150 patients of both sexes and within a age group range of 18 - 80 years who presented to the surgical department were subjected to the study, using Upper Gastro Intestinal Endoscopy as a diagnostic tool to identify the prevalence of various dyspeptic conditions based on their demography. All the findings were recorded and analysed.

Table -1: Age wise distribution

\begin{tabular}{|l|c|c|}
\hline Age group & Total & \% \\
\hline $18-30$ & 34 & 22.6 \\
\hline $31-40$ & 39 & 26 \\
\hline $41-50$ & 37 & 24.6 \\
\hline $51-60$ & 20 & 13.3 \\
\hline $61-70$ & 12 & 8 \\
\hline $71-80$ & 08 & 5.3 \\
\hline
\end{tabular}


Fig 1: Age distribution

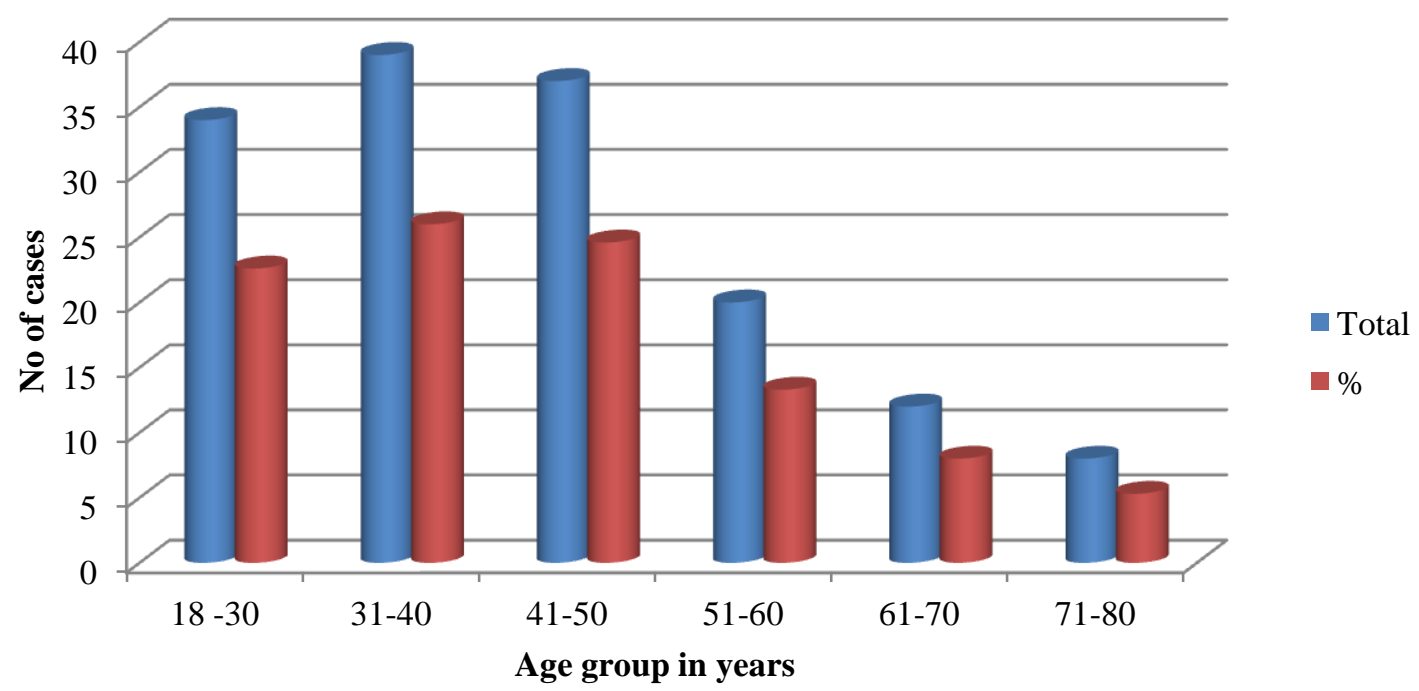

Table 2: Male Vs Female comparison of various diagnosis

\begin{tabular}{|l|c|c|c|c|c|}
\hline S. No & Diagnosis & Male & \% & Female & \% \\
\hline 1 & Normal & 16 & 37.3 & 27 & 62.7 \\
\hline 2 & Lax hiatus & 01 & 25 & 03 & 75 \\
\hline 3 & Hiatus hernia & 11 & 78.5 & 03 & 21.5 \\
\hline 4 & Eosophageal stricture & 02 & 100 & 00 & 0 \\
\hline 5 & Gastric outlet obstruction & 02 & 50 & 02 & 50 \\
\hline 6 & Gastritis & 32 & 74.4 & 11 & 25.6 \\
\hline 7 & Duodenitis & 05 & 71.4 & 02 & 28.6 \\
\hline 8 & Carcinoma stomach & 03 & 75 & 01 & 25 \\
\hline 9 & Antral polyp & 00 & 0 & 01 & 100 \\
\hline 10 & Duodenal ulcer & 03 & 60 & 02 & 40 \\
\hline 11 & Eosophageal varices & 01 & 100 & 00 & 0 \\
\hline 12 & Eosophagitis & 12 & 75 & 04 & 25 \\
\hline 13 & Gastric ulcer & 03 & 100 & 00 & 0 \\
\hline 14 & Eosophageal candidiasis & 01 & 100 & 00 & 0 \\
\hline 15 & Epiglottic cyst & 00 & 0 & 01 & 100 \\
\hline 16 & Carcinoma duodenum & 00 & 0 & 01 & 100 \\
\hline
\end{tabular}

Fig -2: Male Vs Female comparison of various diagnosis

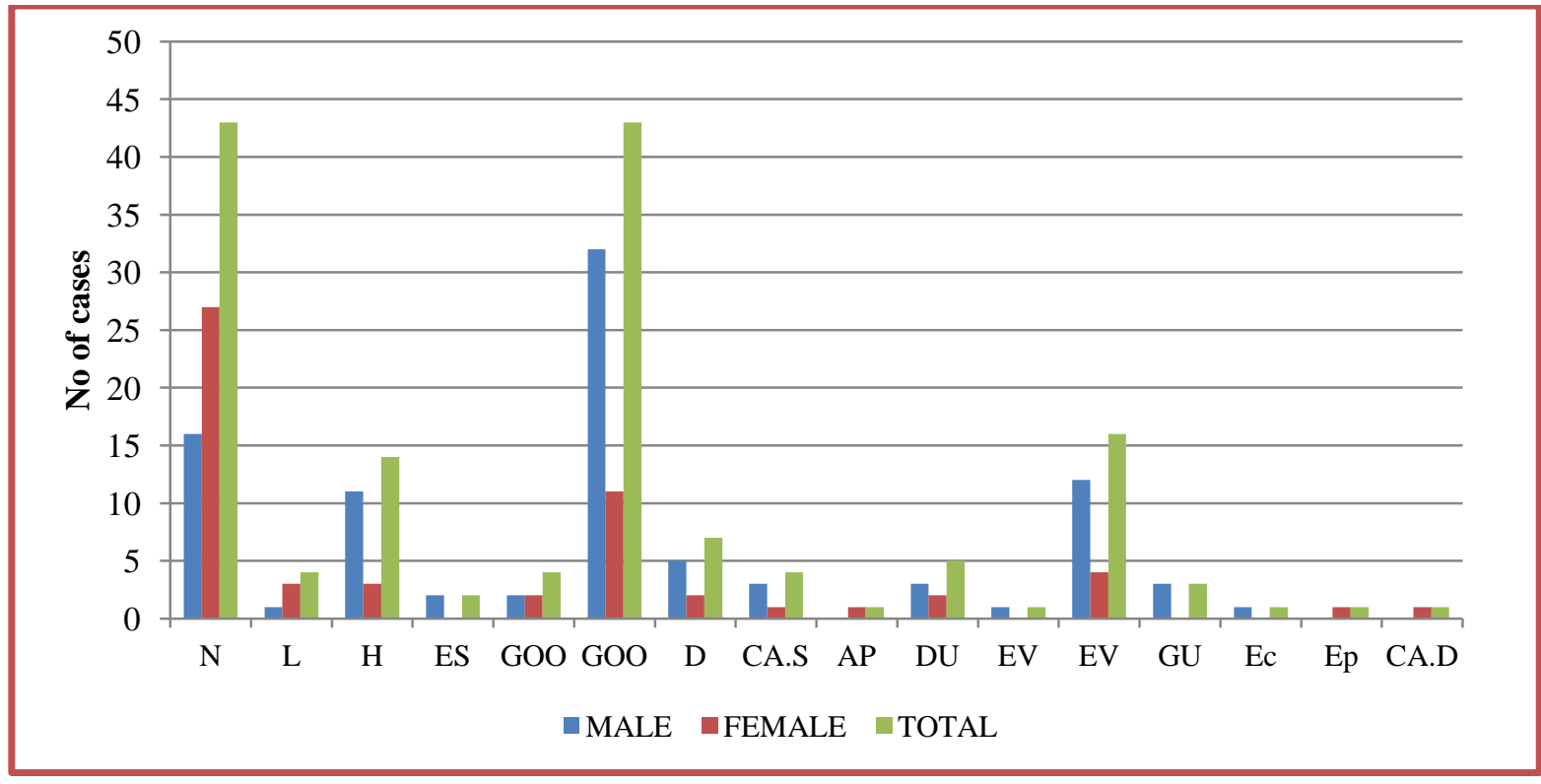


Table 3: Sex wise distribution of various endoscopic findings

\begin{tabular}{|l|c|c|c|}
\hline S. No & Diagnosis & Sex & \% \\
\hline 1 & Normal & F & 67.5 \\
\hline 2 & Lax Hiatus & F & 75 \\
\hline 3 & Hiatus Hernia & M & 78.5 \\
\hline 4 & Eosophageal Stricture & M & 100 \\
\hline 5 & Gastric Outlet Obstruction & M/F & 50 \\
\hline 6 & Gastritis & M & 74.4 \\
\hline 7 & Duodenitis & M & 71.4 \\
\hline 8 & Carcinoma Stomach & M & 75 \\
\hline 9 & Antral Polyp & F & 100 \\
\hline 10 & Duodenal Ulcer & M & 60 \\
\hline 11 & Eosophageal Varices & M & 100 \\
\hline 12 & Eosophagitis & M & 75 \\
\hline 13 & Gastric Ulcer & M & 100 \\
\hline 14 & Eosophageal Candidiasis & M & 100 \\
\hline 15 & Epiglottic Cyst & F & 100 \\
\hline 16 & Carcinoma Duodenum & F & 100 \\
\hline
\end{tabular}

Fig 3: Radar chart depiction of sex distribution in $\%$

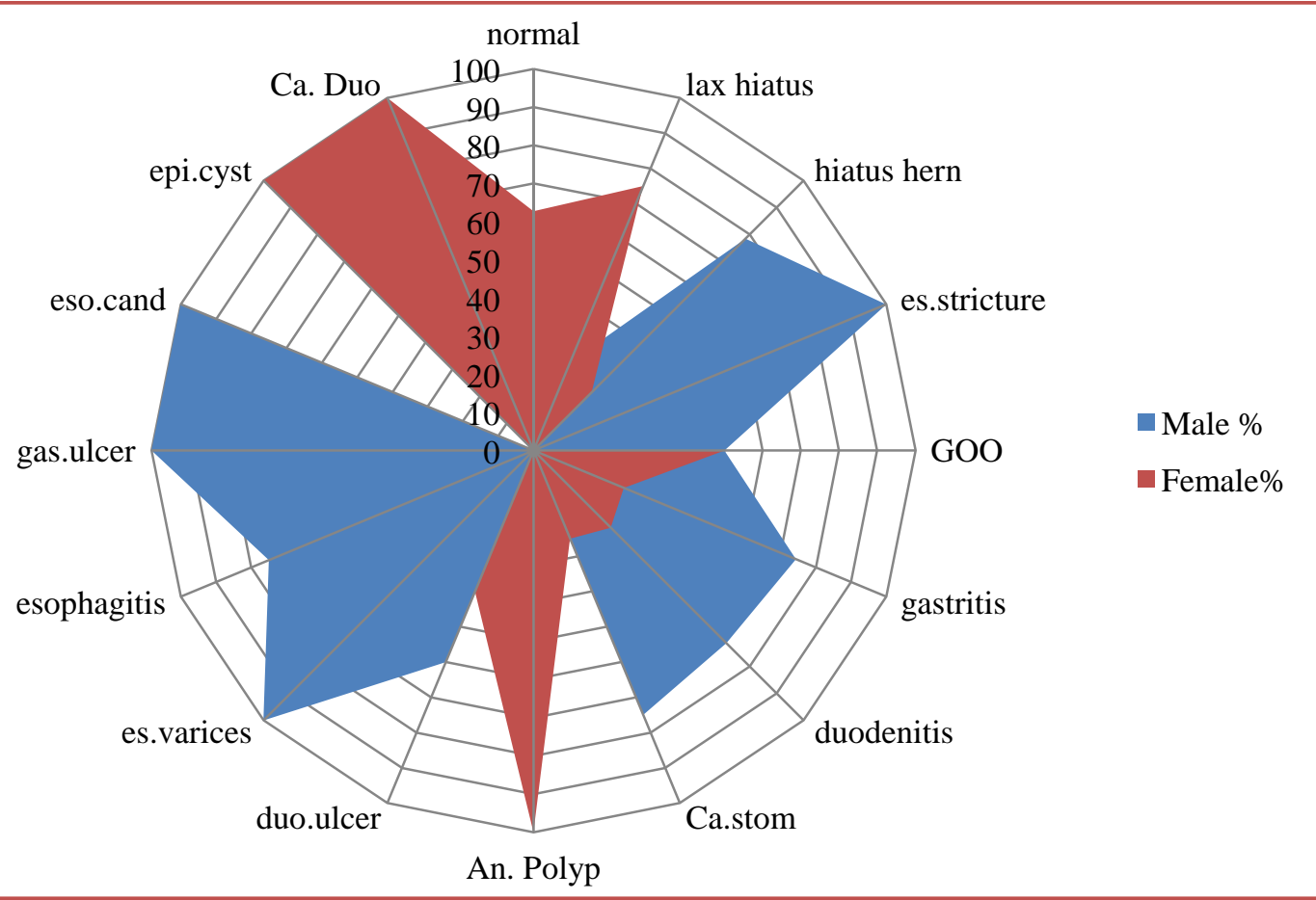


Fig 4: Sex distribution

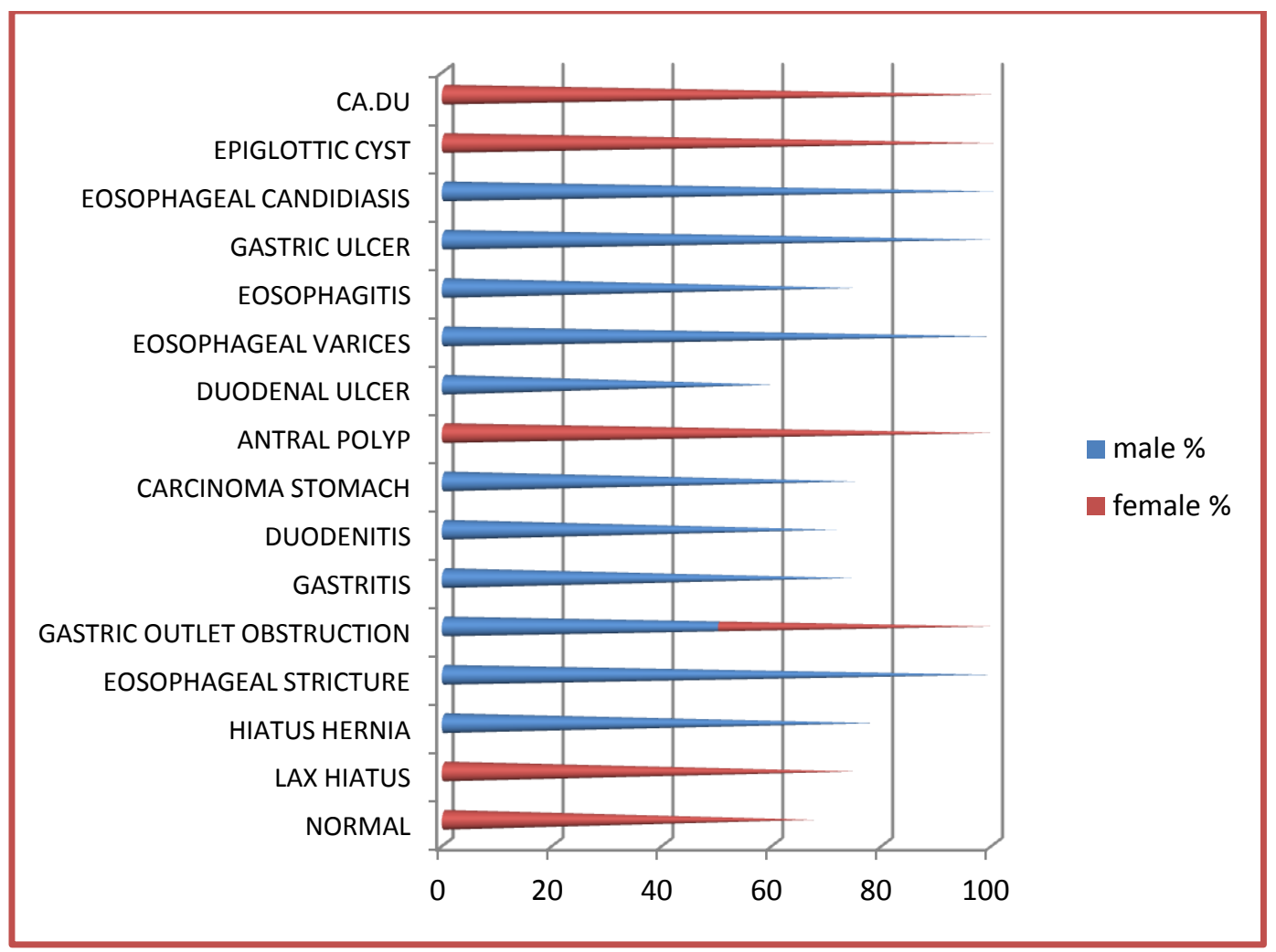

Table 4: Most common cause of GERD

\begin{tabular}{|l|c|c|c|c|}
\hline S. No & Diagnosis & \% & M/F & \% \\
\hline 1 & Gastritis & 28.7 & M & 74.4 \\
\hline 2 & Esophagitis & 10.6 & M & 75 \\
\hline 3 & Hiatus hernia & 10 & M & 78.5 \\
\hline
\end{tabular}

Fig 5: Most common cause of GERD

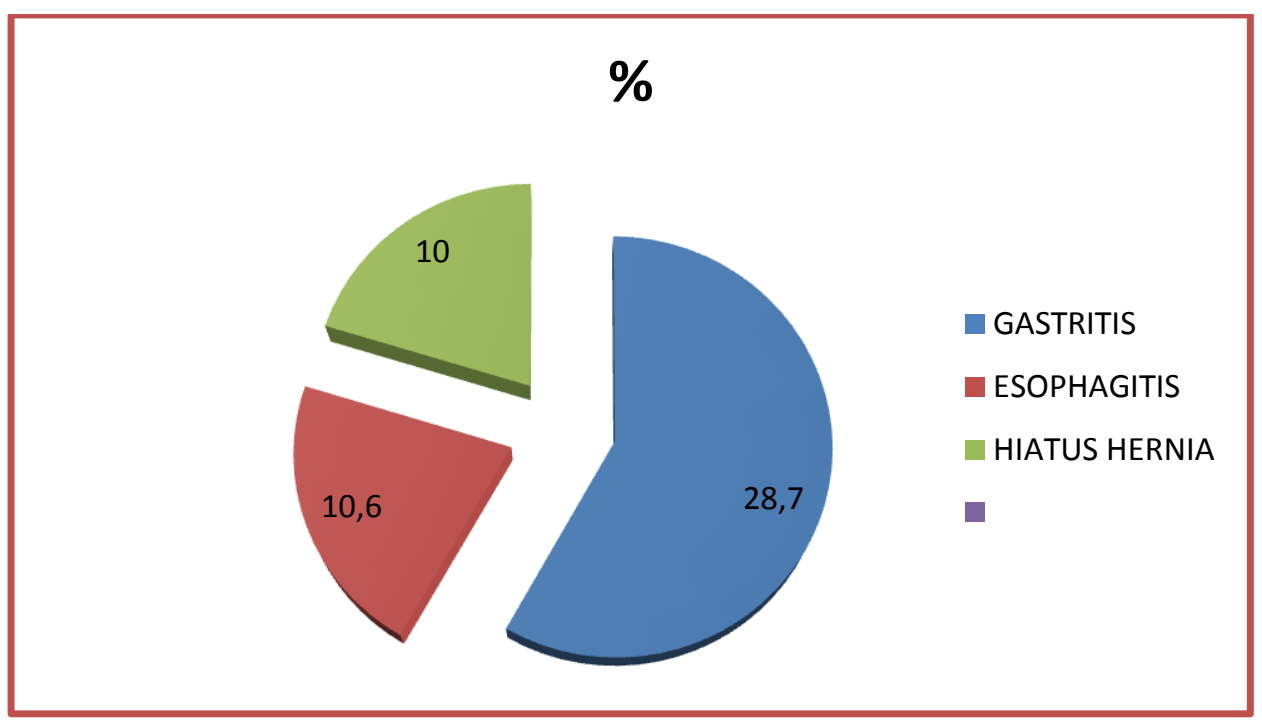

Majority of the cases of dyspepsia were Gastritis, Esophagitis and Hiatus hernia of which most of them were male patients.

All patients were subdivided into different age groups.

- Most common clinically significant endoscopic findings were seen in age group between 31-50 years.

- Hiatus hernia GERD were commonly seen in the age group between 21-40 years

- Inflammatory lesions (gastritis, esophagitis, eso polyp, Barrett's 
esophagus, esophagogastritis, duodenitis, gastroduodenitis esophagogastroduodenitis) and commonly seen in the age group between 31-50 years.
- Ulcer dyspepsia were commonly seen in the age group between 51-80 years

- Malignant lesions were seen frequently in patients aged more than 60 years.

Table 4: Frequency of various diseases on endoscopy in males and females

\begin{tabular}{|l|c|c|c|c|c|c|c|c|}
\hline Gender & Normal study & H.H/ Gerd & Infla lesion & Malig & Ulcer & Others & Total & $\%$ \\
\hline Male & $\begin{array}{c}16 \\
(17.4 \%)\end{array}$ & $\begin{array}{c}12 \\
(13 \%)\end{array}$ & $\begin{array}{c}49 \\
(53.3 \%)\end{array}$ & $\begin{array}{c}03 \\
(3.3 \%)\end{array}$ & $\begin{array}{c}06 \\
(6.5 \%)\end{array}$ & $\begin{array}{c}06 \\
(6.5 \%)\end{array}$ & 92 & $61.3 \%$ \\
\hline Female & $\begin{array}{c}27 \\
(46.7 \%)\end{array}$ & $\begin{array}{c}06 \\
(10.3 \%)\end{array}$ & $\begin{array}{c}17 \\
(29.3 \%)\end{array}$ & $\begin{array}{c}02 \\
(3.4 \%)\end{array}$ & $\begin{array}{c}02 \\
(3.4 \%)\end{array}$ & $\begin{array}{c}04 \\
(6.9 \%)\end{array}$ & 58 & $38.7 \%$ \\
\hline Total & $\begin{array}{c}43 \\
(28.7 \%)\end{array}$ & $\begin{array}{c}18 \\
(12 \%)\end{array}$ & $\begin{array}{c}66 \\
(44 \%)\end{array}$ & $\begin{array}{c}05 \\
(3.3 \%)\end{array}$ & $\begin{array}{c}08 \\
(5.3 \%)\end{array}$ & $\begin{array}{c}10 \\
(6.7 \%)\end{array}$ & 150 & $100 \%$ \\
\hline
\end{tabular}

Fig 6: Frequency of various diseases on endoscopy in different males and females

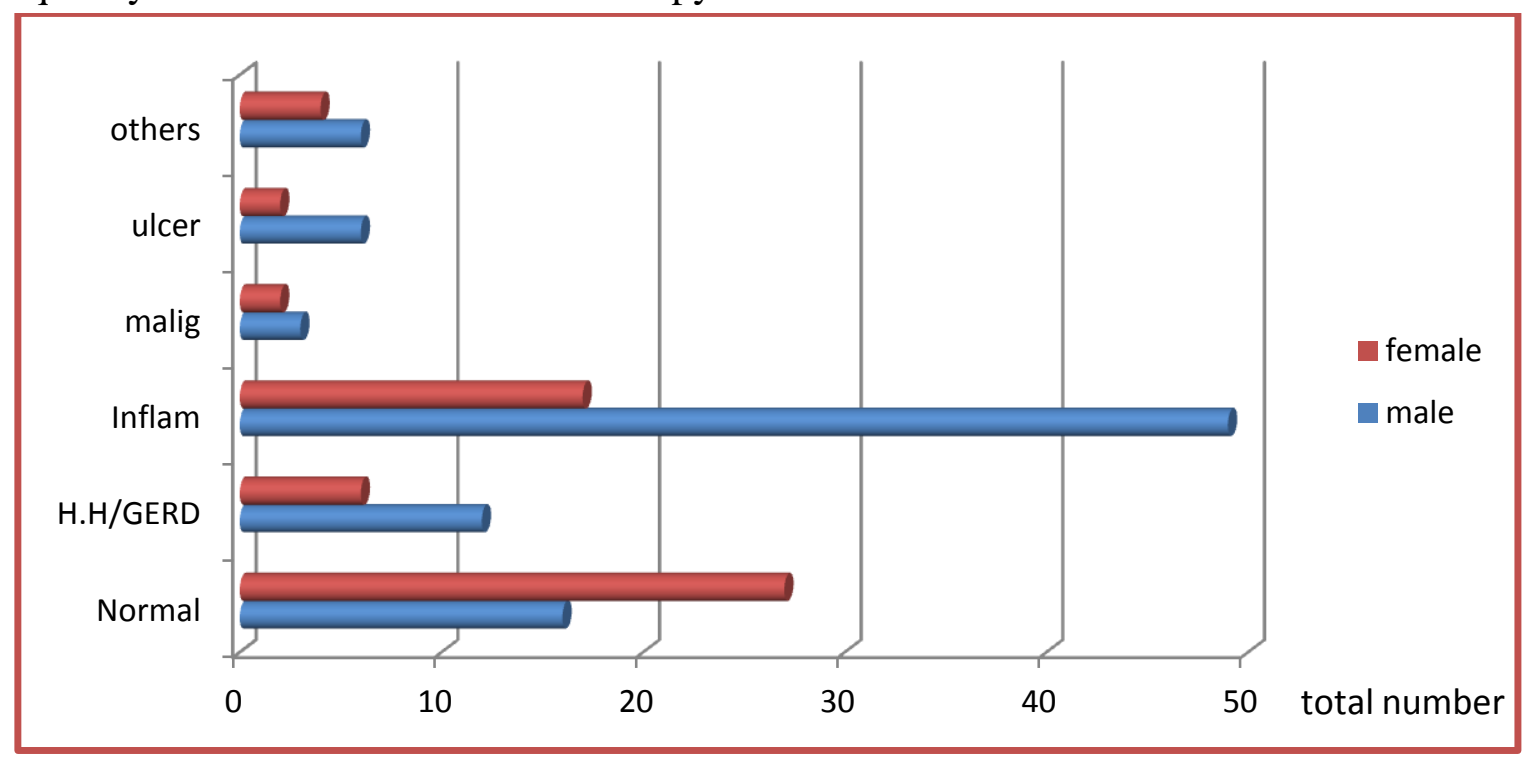

Fig 7: Frequency of various diseases on endoscopy in different males and females in \%

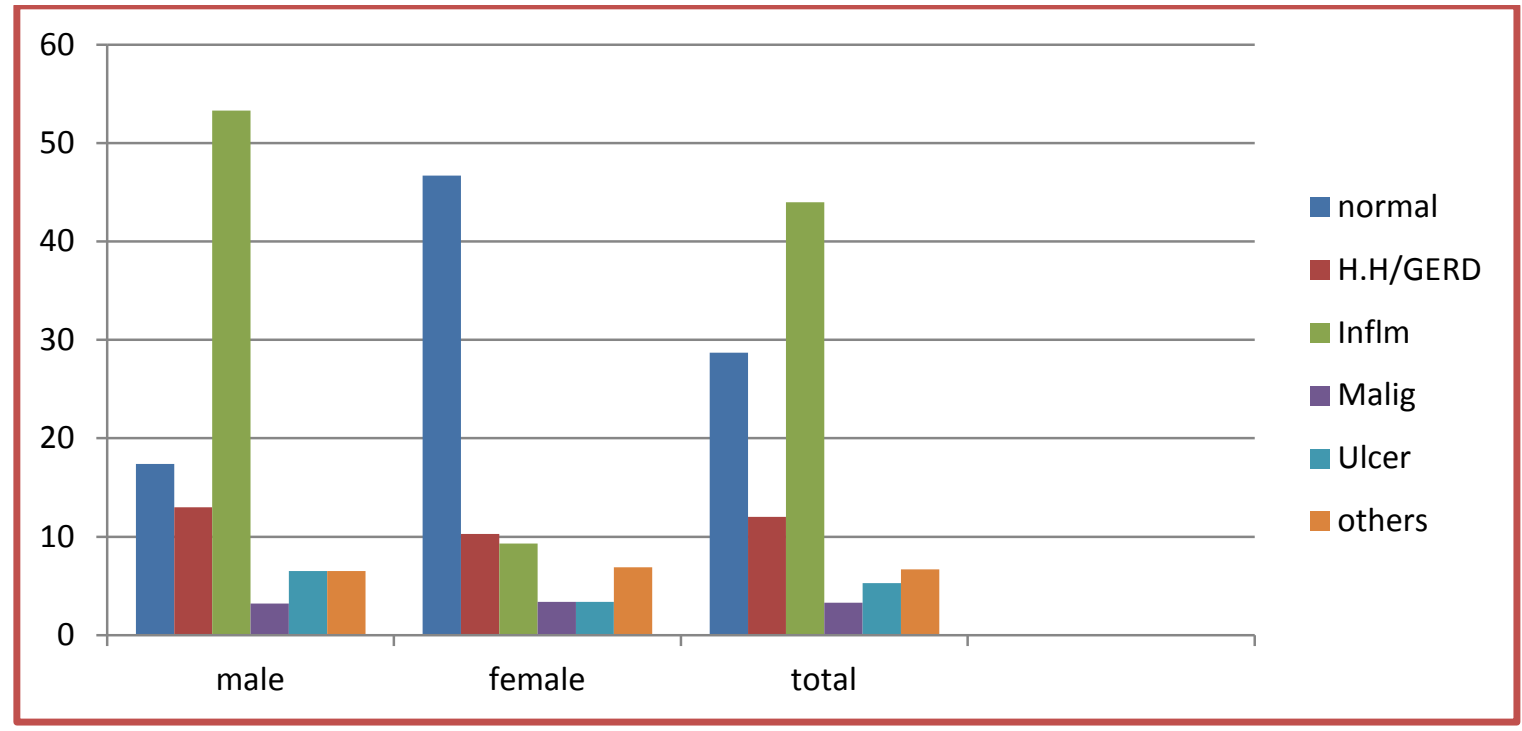




\section{JMSCR Vol||08||Issue||10||Page 311-321||October}

Analysis of various diseases on endoscopy showed that the most common pathology was inflammatory lesions seen in 66 (44\%) of patients, of which $49(53.3 \%)$ were male patients and 17 (9.3\%) were female patients, followed by Hiatus hernia and GERD were next common abnormal findings, $18(12 \%)$ in the decreasing order of the frequency of which $12(13 \%)$ were males and 06 $(10.3 \%)$ females. Ulcer dyspepsia was seen in 08 $(5.3 \%)$ of which $6(6.5 \%)$ males and $2(3.4 \%)$ females. Malignancy was common $3(3.2 \%)$ in males of total $5(3.3 \%)$ patients.

Table 5: Prevalence of clinically significant endoscopic finding according to the site of lesions

\begin{tabular}{|l|c|c|c|c|c|}
\hline S. No & CSF & Male & Female & Total & Percentage \\
\hline 1 & ESOPHAGUS & 17 & 5 & 22 & $20.6 \%$ \\
\hline 2 & STOMACH & 38 & 13 & 51 & $47.7 \%$ \\
\hline 3 & DUODENUM & 8 & 5 & 13 & $12.1 \%$ \\
\hline 4 & ESO+STO & 11 & 6 & 17 & $15.9 \%$ \\
\hline 5 & STO+DUO & 2 & 2 & 4 & $3.7 \%$ \\
\hline 6 & ESO+STO+DUO & 0 & 0 & 0 & $0 \%$ \\
\hline & Total & 76 & 31 & 107 & $100 \%$ \\
\hline
\end{tabular}

Fig 8: Prevalence of clinically significant endoscopic findings according to the site of lesion

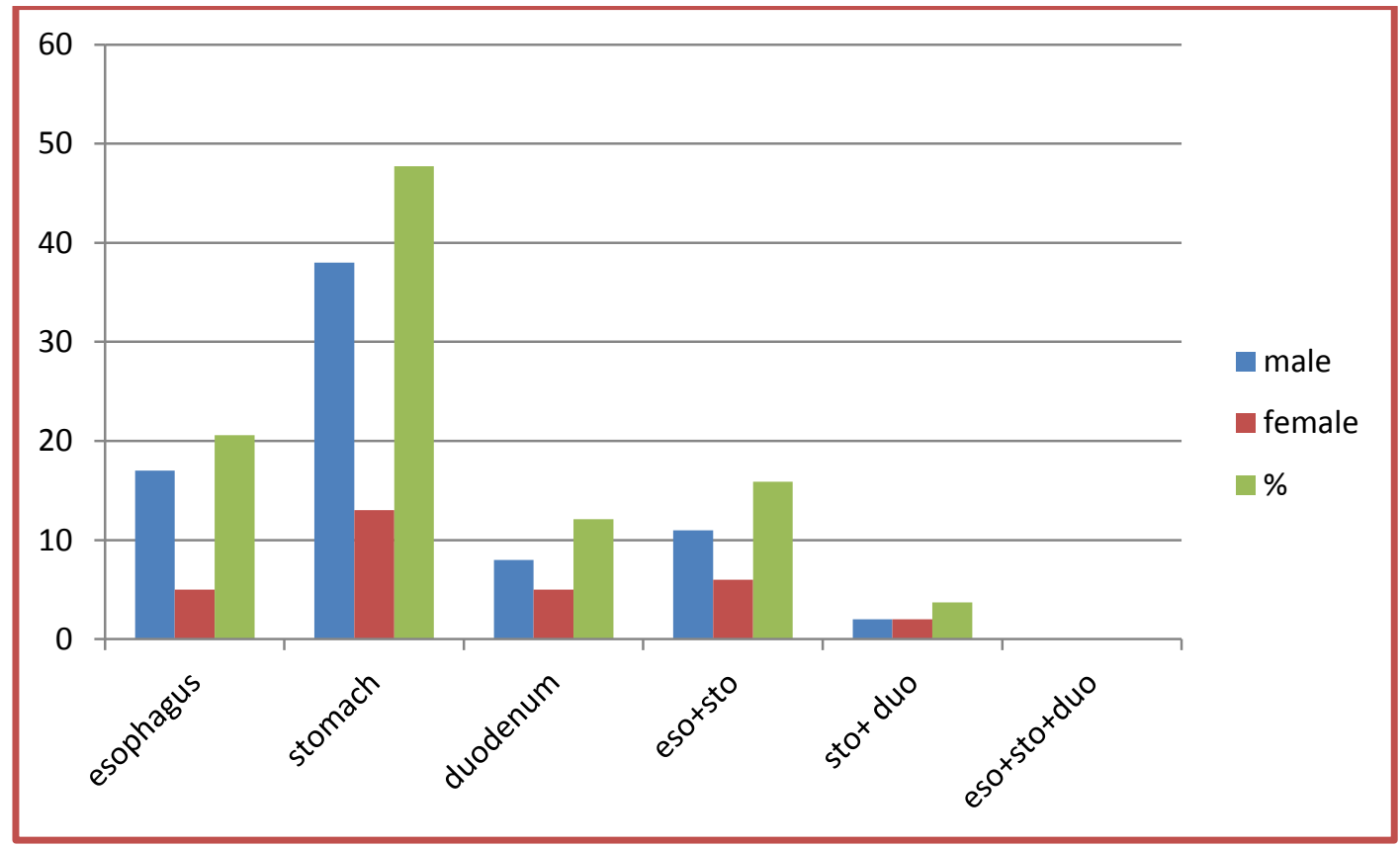

Out of 107 patients with clinically significant endoscopic findings, most common pathology was seen in stomach of $51(47.7 \%)$, patients followed by esophagus $22(20.6 \%)$ and esophagus with stomach 17 (15.9\%). Both males \&females had more lesions in stomach. 


\section{JMSCR Vol ||08||Issue $\|10\|$ Page 311-321||October}

Table-6 Frequency of various symptoms of dyspepsia in males and females

\begin{tabular}{|l|c|c|c|c|c|}
\hline S. No & Clinical presentation & Male & Female & Total & $\%$ \\
\hline 1 & Epigastric pain & 65 & 50 & 115 & $76.7 \%$ \\
\hline 3 & Heart burn & 60 & 32 & 92 & $61.3 \%$ \\
\hline 4 & Nausea/vomiting & 40 & 20 & 60 & $40 \%$ \\
\hline 5 & Food intolerance & 39 & 11 & 50 & $33.3 \%$ \\
\hline 6 & Indigestion & 42 & 16 & 58 & $38.7 \%$ \\
\hline
\end{tabular}

Fig -9 Frequency of various symptoms of dyspepsia in males and females

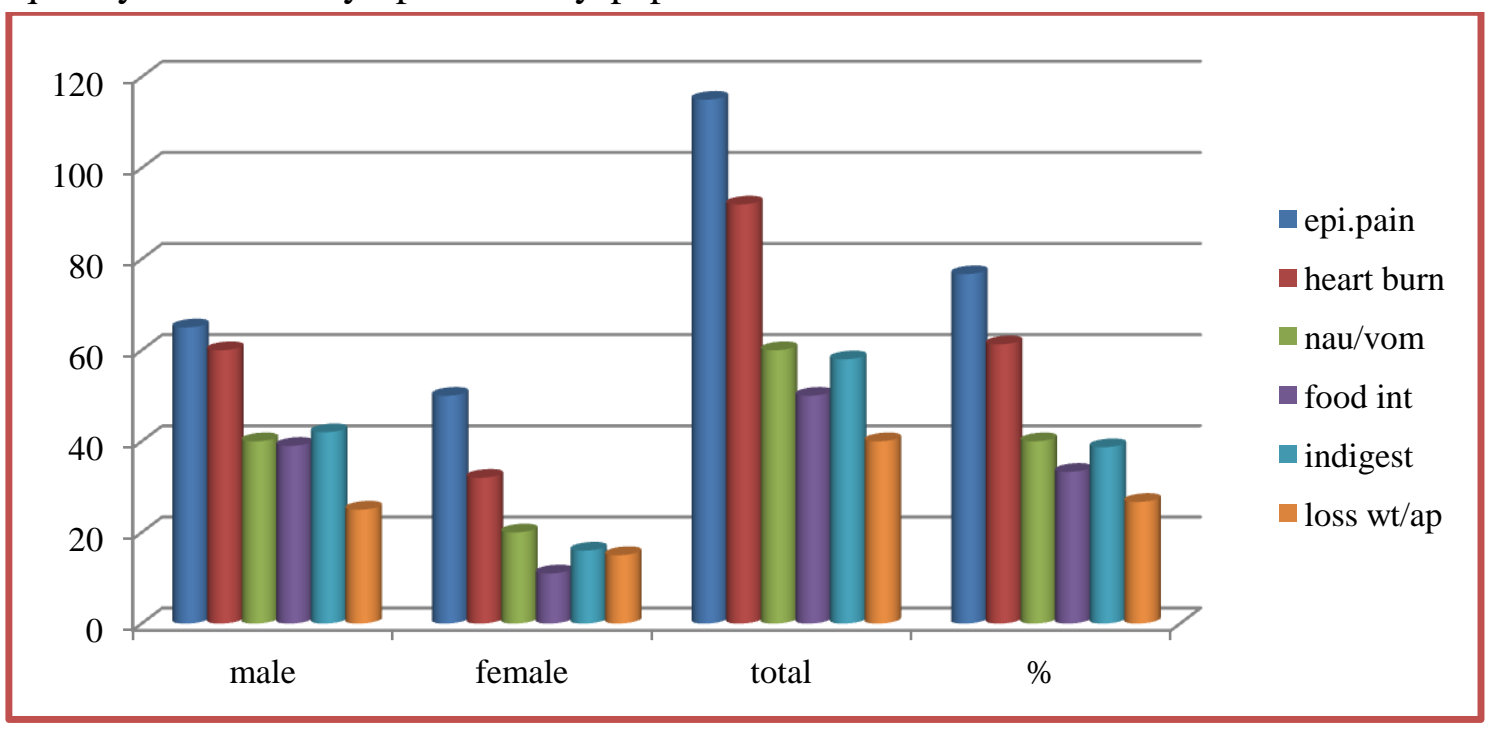

Out of 150 patients, the most common component of dyspepsia was epigastric pain and discomfort, seen in $115(76.7 \%)$ patients, followed by heart burn in $92(61.3 \%)$ patients nausea and/or vomiting 60(40\%) patients, food intolerance in 50 (33.3\%) patients, indigestion in 58 (38.7\%) patients and loss of appetite and/or weight in 40 $(26.7 \%)$ patients.

\section{Comparison of Gender Distribution}

In this study $92(61.3 \%)$ were male patients, 58 $(38.7 \%)$ were female patients. The incidences of different presentations of late onset dyspepsia were common in males compared to females. The male / female ratio in the studies conducted by Khan $\mathrm{N}$ et al - 2.3:1, Ziauddin- 1.6:1, Mustapha SK et al- 1.1:1 respectively. In these studies also the majority of patients were males as observed in our study.
Comparison of Incidence of Gastric Malignancies

In this study there were 04 patients with carcimona stomach accounting for $2.7 \%$, among them which 3 were male patients. Gastric malignancies were common in older age groups. Incidence of gastric malignancies observed by various authors are as follows:

Table-7: The incidence of gastric malignancy in these studies is comparable with the observed in the present study

\begin{tabular}{|l|c|c|}
\hline S. No & Name of study & $\begin{array}{c}\% \text { Gastric } \\
\text { Malignancies }\end{array}$ \\
\hline 1 & Choomsri P et al.5 & $1 \%$ \\
\hline 2 & Khan N et al.6 & $3 \%$ \\
\hline 3 & Ziauddin40 & $4 \%$ \\
\hline 4 & Present study & $2.7 \%$ \\
\hline
\end{tabular}

\section{Results}

- Highest prevalence of late onset dyspepsia in the age group of 41-50years $(24.6 \%)$ 
- Dyspepsia was more common in males $(61.3 \%)$ when compared to females

- Clinically significant endoscopic findings were observed in $71.3 \%$ of patients with uninvestigated dyspepsia.

Out of 150 patients, there were 92 (61.3\%) male patients, 58 (38.7\%) female patients, age ranging from 18 years to 80 years. The mean age of the patients in this study with more GERD was found to be between $31-40$ years.

Most patients presented with a complex of three or more dyspeptic symptoms and the symptom profile was not predictive of the endoscopic findings. However, the high prevalence of gastritis (28.7\%), suggests that most patients of both sexes presenting with uninvestigated dyspepsia can be safely managed initially with acid suppressive drugs.

\section{Conclusion}

Clinically significant endoscopic findings were observed in $71.3 \%$ of patients with uninvestigated dyspepsia. Most of the dyspeptic conditions were seen in middle age group in the range between 30 - 50 years. Male had predominance over females. Inflammatory lesions [ mostly Gastritis], GERD and malignancy was found more common in males. Most patients presented with a complex of three or more dyspeptic symptoms and the symptom profile was not predictive of the endoscopic findings. A larger number of inflammatory lesions as a result of increased acid production and low incidence of malignancy in the study group. It is suggested that the uninvestigated patients with dyspepsia may be initially managed medically with acid suppressive therapy, diet and life-style modification.

Endoscopy may be undertaken in patients with recurrent symptoms or in whom drug therapy fails.

Declaration of Conflict of Interest: There is no conflict of interest

Funding: Nil
This research received no specific grant from any funding agency in the public, commercial, or notfor-profit sectors.

\section{References}

1. Talley NJ. Dyspepsia: how to manage and how to treat?. Aliment Pharmacol Ther. 2002;16 (4) :95-104.

2. Drossman DA, Corazziari E, Talley NJ et al. The functional gastrointestinal disorders. 2nd ed. In: Diagnosis, Pathophysiology and Treatment: a Multinational Consensus. Degon: McLean, Virginia;2000.

3. Westbrook JI, McIntosh JH, Talley NJ. The impact of dyspepsia definition on prevalence estimates: considerations for future researchers. Scand J Gastroenterol. 2000; 35:227-33.

4. Talley NJ, Holtmann G. New concepts in functional gastrointestinal diseases: functional dyspepsia and its link to other disorders. In: Textbook of Gastroenterol. Philadelphia, Lippincott Williams and Wilkins;2001.

5. Choomsri $\mathrm{P}$ et al. Upper gastrointestinal endoscopic findings in patients presenting with dyspepsia. Thai J Surg. 2010;31:7-12.

6. Khan $\mathrm{N}$ et al. Upper gastrointestinal endoscopic assessment of patients presenting with dyspepsia. JPMI. 2007;21(3):212-6.

7. Thomson A B R et al. The prevalence of clinically significant endoscopic findings in primary care patients with uninvestigated dyspepsia: The Canadian Adult Dyspepsia Empiric TreatmentPrompt Endoscopy (CADET-PE) study. Aliment Pharmacol Ther. 2003; 17: 148191.

8. Delaney BC, Wilson S, Roalfe A et al. Cost effectiveness of initial endoscopy for dyspepsia in patients over age 50 years: A randomized controlled trial in primary care. Lancet. 2000; 356:1965-9.

9. Wiklund I, Glise H, Jerndal P et al. Does 
endoscopy have a positive impact on quality of life in dyspepsia ? Gastrointest Endosc. 1998;47:449-54.

10. Sandler RS, et al: The burden of selected digestive diseases in the United States. Gastroenterol. 2002; 122:1500.

11. Owen DA: Gastritis and carditis. Mod Pathol. 2003;16:325. National Institute for Health and Clinical Excellence: Clinical guideline Dyspepsia. London;2004:17.

12. Hungin A, Thomas $\mathrm{P}$, Bramble $\mathrm{M}$, et al. What happens to patients following open access gastroscopy? An outcome study from general practice, $\mathrm{Br} \mathrm{J}$ Gen Pract. 1994;44:519-21.

13. Mary Maish. Esophagus.18th ed. In: Sabiston Textbook of Surgery (2)Townsend, Beauchamp eds. Philadelphia. Saunders. 2008: pp.1049107.

14. Jeffrey H. Esophagus and Diaphragmatic Hernia, 8th ed. In: Schwartz"es Principles of Surgery, U.S.A, McGraw- Hill; 2005:pp 835-931.

15. Ganong W F. Regulation of gastrointestinal function. 20th ed. In: Review of Medical Physiology,Ganong WF, ed. USA. McGraw-Hill Company;2001: pp 439.

16. Koloski NA et al. Epidemiology and health care seeking in the functional GI disorders; a population- based study. Am J Gastroenterol. 2002;97:2290-9.

17. Dyspepsia: Managing dyspepsia in adults in primary care, evidence based clinical practical guideline, 2004; North of England dyspepsia guideline development group, center for health services, Research report no. 112, University of New Castle, ISDN 0-9540161-7-3.

18. Brzozowski, Tomasz MD, Konturek et al. Involvement of Endogenous Cholecystokinin and Somatostatin in gastroprotection induced by intraduodenal fat. J Clin Gastroenterol. 1998; 27(1):12537.
19. Kenneth A. History and Development of Flexible Endoscopy. In: Mastery of Endoscopic and Laparoscopic Surgery, Eubanks, Swanstrom, Soper, eds.USA, Lippincott Williams and Wilkins;2000:pp 3-6.

20. Bruce V. Diagnostic Upper Gastrointestinal Endoscopy, Mastery of Endoscopic and Laparoscopic Surgery, Eubanks, Swanstrom, Soper, eds. USA,Lippincott Williams and Wilkins; 2000;115-22.

21. Mitsuo, Sotaro. Fibergastroscopic Examination. 1st ed. In:Fiberscopy of diseases, Tsuneoka, Kenji, eds. Tokyo ,Igaku Shoin Ltd;1973: pp

22. Talley NJ, Vakil N. "Guidelines for the management of dyspepsia". Am J Gastroenterol. 2005;100 (10):2324-37. National Institute for Health and Clinical Excellence. Dyspepsia. 2004,August.

23. Talley NJ, Stanghellini V, Heading RC, Koch KL, Malagelada JR, Tytgat GN. "Functional gastroduodenal disorders". Gut. 1999; 45 (2): 1137-42.

24. Talley NJ, Phung N, Kalantar JS . ABC of the upper gastrointestingal tract: Indigestion: When is it functional? $\mathrm{Br}$ Med J. 2001; 323 (7324): 1294-7.

25. Talley NJ, Weaver AL, Tesmer DL, Zinsmeister AR (1993). "Lack of discriminant value of dyspepsia subgroups in patients referred for upper endoscopy". Gastroenterol. 105 (5): 1378-86.

26. Dyspepsia: Managing dyspepsia in adults in primary care, evidence based clinical practical guideline, 2004; North of England dyspepsia guideline development group, center for health services, Research report no. 112, University of New Castle, ISDN 0-9540161-7-3.

27. American Gastroenterology Association Technical Review on the Evaluation of Dyspepsia. Gastroenterol. 2005;129:175680.

28. Goh K L. "Update of management of 
Helicobacter pylori infection, including drug-resistant organisms.” J Gastroenterol Hepatol. 2002 17(4): 482-487.

29. Sarwar M et al. Endoscopic assessment of Dyspepsia. Pak Armed Forces Med J. 2004;54: 48-50.

30. Ziauddin. Endoscopic findings in Dyspepsia a prospective study of 200 cases J Postgrad Med Inst. 2003;17 (2) :235-9.

31. Koloski NA et al. Epidemiology and health care seeking in the functional GI disorders; a population- based study. Am J Gastroenterol. 2002;97:2290-9.

32. Wulfen Von, Heeseman J, Butzow et al. "Detection of C. pyloridis in patients with antral gastritis and peptic ulcers by culture, compliment fixation test and immunoblot." J Clin Microbiol.1986; 24: 716-9. 